\title{
Evolution Game Model of Travel Mode Choice in Metropolitan
}

\author{
Chaoqun $\mathrm{Wu}^{1,2}{ }^{1,2}$ Yulong Pei, ${ }^{3}$ and Jingpeng Gao ${ }^{4}$ \\ ${ }^{1}$ School of Transportation Science and Engineering, Harbin Institute of Technology, Harbin 150090, China \\ ${ }^{2}$ School of Automobile and Traffic Engineering, Heilongjiang Institute of Technology, Harbin 150050, China \\ ${ }^{3}$ Traffic College, Northeast Forestry University, Harbin 150040, China \\ ${ }^{4}$ College of Information and Communication Engineering, Harbin Engineering University, Harbin 150001, China
}

Correspondence should be addressed to Chaoqun Wu; wuchaoqunwcq@126.com

Received 11 May 2015; Accepted 16 July 2015

Academic Editor: Kamel Barkaoui

Copyright (C) 2015 Chaoqun Wu et al. This is an open access article distributed under the Creative Commons Attribution License, which permits unrestricted use, distribution, and reproduction in any medium, provided the original work is properly cited.

\begin{abstract}
The paper describes an evolution game model of travel mode choice to determine whether transportation policies would have the desired effect. The model is first expressed as a two-stage sequential game in the extensive form based on the similarity between evolution game theory and the travel mode choice process. Second, backward induction is used to solve for Nash equilibrium of the game based on the Folk Theorem. Third, the sensitivity analysis suggests that a payoff reduction of travel by any mode will result in a rising proportion of inhabitants travelling by that mode and falling proportions of inhabitants travelling by other modes. Finally, the model is applied to Beijing inhabitants' travel mode choices during morning peak hours and draws the conclusion that the proportion of inhabitants travelling by rail would increase when traffic congestion is more severe. This confirms that fast construction of the urban rail transit would be an effective means of alleviating traffic congestion. The model may be a useful tool for policy makers for analyzing the complex influence of travel mode choice processes on transport policies and transport construction projects.
\end{abstract}

\section{Introduction}

Inhabitant travel mode choice affects demand for transportation and transport system supply, and it is influenced by various factors that can be divided into individual traveler's factors and travel context factors.

Traveler's individual factors originate not only from sociodemographic considerations, but also from consciousness. Sociodemographic factors affecting travel mode choice include age, gender, and identification, while consciousness depends on individual sociodemographic aspects and travel contexts.

Travel mode choice is influenced to some degree by an inhabitant's age and gender. School travel mode of children has been associated with their physical activity [1]; travel mode of the elderly has been associated with personal, household, and neighborhood characteristics and trip purpose [2]; women exhibit less willingness to travel by car [3]. However, identities should also be included in the complex mix of factors affecting travel mode [4].
In a way, travel mode depends on individual identity. Choosing a travel mode, parents must take work flexibility and children's age and gender into account [5]. Journeybased effects, on personal space, autonomy, and identity [6] have caused commuters to choose between travel by public transport or by private car to go to work. Survey data from 2,096 convenience store customers within and outside the Greater London Metropolitan Area reveals that proximity to home is the most significant variable that may encourage customers to visit on foot [7]. If a car must be used in touring, since it must be returned home at the end of the tour, it will usually be used during the entire travel chain [8]. A traveler's identity in this way dictates travel consciousness.

Consciousness also drives travel mode choice. "Beliefs could not be differentiated into attitudinal and intention and perceived behavioral control constructs, but seven beliefs predicted the theory of planned behavior cognitions [9]." General values and beliefs have influenced intentions primarily through specific beliefs held regarding the railway line [10], and the youngest age group has been more open to change 
and demonstrated stronger intentions to use new railways. Travel satisfaction has been affected by building an environment travel-related attitude and this in turn has seemed to influence future mode choices [11]. Travel mode choice also might affect communities through the influence of social judgments [12]. These various beliefs about travel modes and inhabitants travel satisfaction should be considered in evaluating travel contexts and may guide the development of such contexts.

Travel context generally includes the transport service, the built environment, social contact, and even the natural environment. Real-time traffic information has helped commuters make informed decisions regarding their travel mode choices [13]. The built-up environment near a child's residence has been more strongly associated with mode choice than the built environment around the school [14]. The travel mode choice difference between two groups whose social contact is maintained separately through an ego network and a spatial neighborhood revealed that mode choice has been explored not only with respect to traditional socioeconomic, attitudinal, and trip characteristic variables, but also with respect to egocentric social-networking factors related to the behaviors of social contacts [15]. Meanwhile, daily commuters may contribute disproportionately to overall daily inhalation of urban-air contaminants, and the car mode, on average, has exhibited the highest concentrations for such contaminants [16], even though much of the air pollution has been insulated by the car filtration system; the mean exposure to such contaminants while walking is therefore greatly in excess of that while driving [17]. The travel context is thus a platform of the mode choice, and travel habits will be gradually made based on the reciprocity between travel context and individual consciousness.

Travel-behavior habits are a joint result of individual consciousness and travel context. As early as 1994, Bas Lanken, Henk Aarts, and Ad van Knippenberg focused on general habits in the process of travel-mode choice, and they concluded that "when habit is strong the attitude-behavior relation is weak [18]"; that is, individuals with ingrained habits with respect to travel mode choice were less likely to change their behavior compared to those with less ingrained habits. When the travel context is stable, a habit may be established by frequent travel and may tend towards stability because of ceiling effects [19] and "dominant behavioral outcomes [20]." When travel context has changed naturally or has been changed, behavioral intentions have been keys to future travel mode choice [21].

Although age, gender, identity, social contact, build environment, and travel-habits of inhabitants may differ on a particular trip, their common purpose is the maximization of individual utility, that is, the minimization of generalized travel cost measured in terms of both travel time and travelling expense. The significance of unit-generalized travel cost varies with individual traveler age, identity, and travel context; there are vast differences, for example, in the wealth created by Bill Gates in one minute, the charm of one dollar to the poor, and the time that Beijing commuters must spend to go home. Travelers' long-term lifecycle habits have an enduring impact when shifted to different mode choices, wherein sensitivities to travel time and cost may vary considerably [22]. Road congestion with fixed peak load may suggest arguments for an additive random delay [23], or adjusting travel cost, quantifying the travel context to select the best travel combinations among a wide variety of travel routes and transportation modes [24].

Considering the individual traveler factors and travel context factors mentioned above, effective ways to study travel mode choice might include statistically analyzing sample data and building a model based on the data analysis.

It is impossible for a survey to cover every inhabitants, but many cities have conducted discontinuous largescale or continuous small-scale travel surveys. The Greater Hobart Household Travel Survey collects information from 200 households each month; The London Travel Demand Survey covered 8,000 households annually via face-to-face interviews; The Metropolitan Washington Council of Governments conducted a 10,000 household survey in 2007; The Fifth Beijing Traffic Comprehensive Survey was launched in September 2014 and covered 40,000 households. Governments and scientific research institutions have also conducted nonscheduled different-sized special investigations focused on special planning or research requirements.

GPS, popular in transportation systems, has been widely used in travel surveys. In Jerusalem, the application of an GPS-assisted method for a large-scale Household Travel Survey proved the power of the GPS approach in creating full and consistent daily records of individual activity-travel patterns [25]. The 5,000 inhabitants wore GPS equipment for 24 hours in the Fifth Beijing Traffic Comprehensive Survey, so a GIS algorithm [26] could be used to automatically process the data from GPS-based travel surveys and be able to offer the more comprehensive and precise data.

Almost all types of modes were encountered in data analysis. A value-attitude-behavior hierarchical model of cognition [27] estimated an integrated choice and latent variable model that assumed hierarchical relationships between the latent variables and flexible substitution patterns across the modal alternatives, using sampled data from 519 German commuters. A two-level structural equation model [28] with trip-specific attributes on level 1 and personspecific attributes on level 2 sampled the 26,865 individual trips of 3,560 students at the Ruhr-University in Bochum and explored interactions between persons and trip-specific variables. An evidential neural network (ENN) for predicting individual travel mode, whose analyzed data set was taken from a survey conducted in 2007, was found to be superior to the studied alternatives through comparison by cross validation [29]. These models have confirmed and reflect the interaction of travel-mode choice and affecting factors, but they have been deficient in simulating the evolution of travel mode choice.

Game theory has been previously investigated as a method for making strategic polices in dealing with transport problems in a number of places in the literatures. Following review of noncooperative game theory on transport analysis [30] by Hollander and Prashker, that method was applied in the following aspects: transit network assessment [31, 32], transportation operation [33-35], emergency evacuation 
due to unexpected disasters $[36,37]$, travel-modes choice $[38,39]$, and so forth. An experimental game [39] was designed for researching commuters' travel mode choices, and an evolutionary game model [38] of travel mode choice between private car and public transport has been based on participants' bounded rationality; the conclusion was that the ratio of choosing the travel modes should evolve into the value expected by managers through adjusting the Single Population Stable Equilibrium Parameter. However, these models discussed only the impact of "pecuniary treatments" on the demand for private car and public transit and struggled to evaluate the impact of measures other than just the economic ones.

This paper also employs game theory to build an evolution game model of travel mode choice. Four travel modes, travels by car, by taxi, by bus, and by rail were considered because, for long-distance metropolitan trips, the proportions of the inhabitants travelling by one of these four modes are the most common structure of travel mode choice. When the structure is stable, the game model reaches a Nash equilibrium, and the change in the Nash equilibrium represents the evolution of travel mode choices. The key aspect of the model is that the payoff function can be used to evaluate the effect of a policy or a policy packages. The payoff function may have a time variable, a monetary variable, both of these, or some other variable determined by the purposes and objects of the model application. The intermediary benefit of the payoff function is that use of this model provides significant value in use, as confirmed in analysis of its application.

\section{Model Approach}

2.1. Evolutionary Game Theory and the Process of Travel Mode Choice. Evolutionary game theory is used in this paper as a vehicle for discussing travel mode choice based on the following apparent similarities:

(a) A group can be a substitute for an individual as a participant in evolutionary game theory, and the proportions of the individuals choosing different pure strategies in the group can substitute for mixed strategy. The results of travel mode choice are group behavior within the travel mode subsystems, and only the proportions of individuals choosing each travel mode are meaningful for management and study.

(b) Group Nash equilibrium means that the frequency of the adopted strategies makes the strategy payoffs exactly equal with no one desiring a change in strategy; then the percentage of individuals choosing each different strategy remains stable and reaches equilibrium. In the stable travel context, a travel mode choice will tend to be stable; the Nash equilibrium of the evolutionary game will be changed by the means of traffic control, the construction, and the improvement of the transportation facilities to keep the system flowing smoothly and efficiently.

(c) The nature of group strategies' acts is that only a bounded-rationality human gets closer to Nash equilibrium by summarizing their experience and adjusting their strategies rather than by using a perfectly rational introspective method and Nash equilibrium analysis such as reasoning. The players can obtain information such as travel time, travel cost, and Traffic Performance Index through dissemination channels like the Internet, and they can observe the historical results and the strategies adopted by the others. The inhabitants observe and experience the service provided by trip modes during their frequent travels and finally determine the optimum approach after summarizing their experience and adjusting their strategies. Although they are bounded by rationality, constantly repeated travel leads the structure of travel mode choice by modes to reach excellent stability.

2.2. Evolutionary Game Model. The extensive form of the sequential, the game displayed in Figure 1, describes the process of travel mode choice. Two hypotheses are embedded in the model.

Hypothesis 1. Metropolitan travelers can be divided two groups: car owners and noncar owners. Travel is a two-stage process: (1) everyone chooses whether to own one or more cars; (2) the car owners will select from one of four modes: car, taxi, bus, or rail, and the noncar owners will select one from the latter three, excluding travel by personal car.

Hypothesis 2. The payoff function that inhabitants must contribute is independent of the proportion of inhabitants travelling in a particular mode.

The extensive form is defined by three objects.

(1) The set of players is $N=\{1,2, \ldots, n\}$; all inhabitants going from one place to another using the urban transport system are players.

(2) The strategy sets of the players are $S_{1}=$ \{Car owner, Noncar owner and $S_{2}=\{$ Travel by car, Travel by taxi, Travel by bus, Travel by rail\}. The two-stage process of the game act corresponds to the two strategy sets.

(3) The payoff functions of the players are $f_{\text {car }}=\pi_{1}, f_{\text {taxi }}=$ $\pi_{2}, f_{\text {bus }}=\pi_{3}$, and $f_{\text {rail }}=\pi_{4}$ which depend on research objects and purposes.

It might be impossible for an inhabitant with a pure strategy to always travel by the same mode with certainty. Everyone may not always travel by one transit, and any group comprising trip units may not do using only one. They actually have a mixed strategy.

A mixed strategy occurs when an individual plays any one of the discrete strategies of a matrix game with a continuous probability between zero and one. The individual using a mixed strategy will have a payoff function based on the probabilities of the mixed strategy. Then, in the travel mode choice game shown in Figure $1, p_{c}$ and $p_{n}$ are the respective probabilities of car owner and noncar owner being in stage 1; in stage 2 the respective probabilities of car owner travelling by car, taxi, bus, or rail are $R_{\text {car }}^{c}, R_{\text {taxi }}^{c}, R_{\text {bus }}^{c}$, and $R_{\text {rail }}^{c}$; the probabilities of the noncar owner travelling by taxi, bus, and rail are $R_{\text {taxi }}^{n}, R_{\text {bus }}^{n}$, and $R_{\text {rail }}^{n}$.

\section{Solving for Nash Equilibrium}

According to the Folk Theorem [40], any payoff vector satisfying individual rationality can be obtained through a set of specific subgame perfect equilibriums in an infinitely 


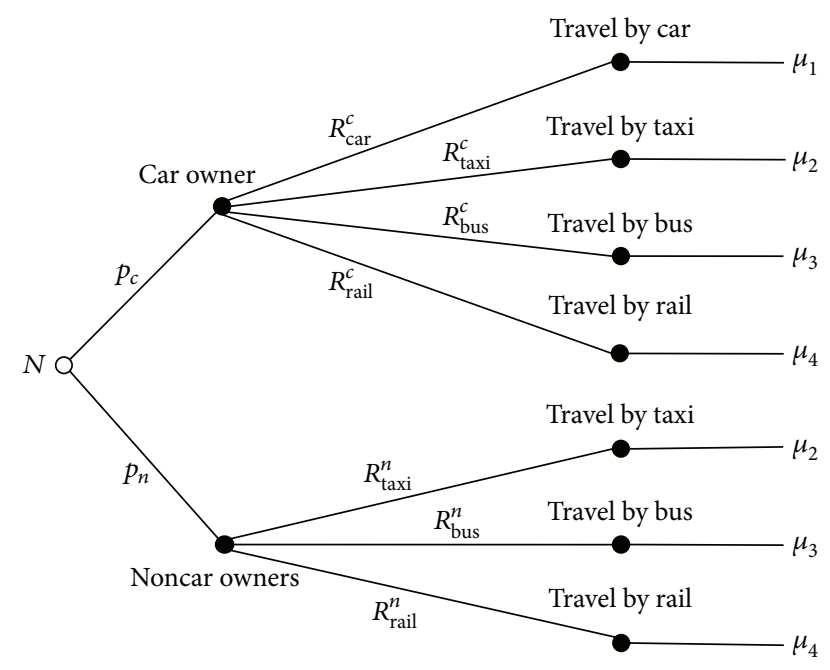

FIgURE 1: Extensive form of travel mode choice game.

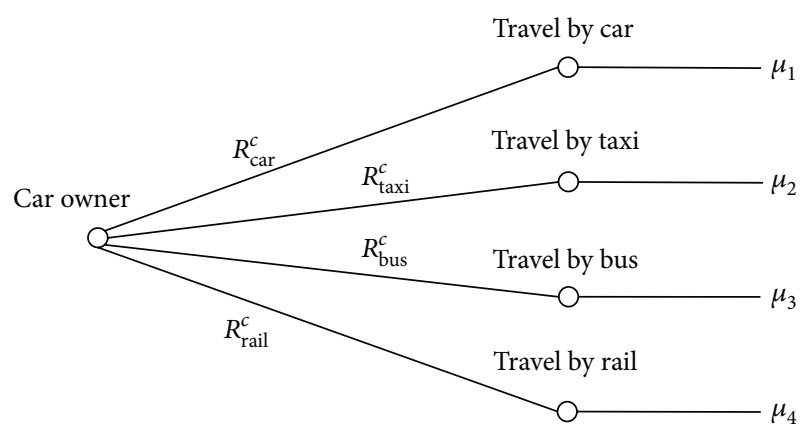

Figure 2: Car Owner Travel Mode Choice Subgame.

repeated game [41]. In the travel mode choice game, there are two subgames: Car Owner Travel Mode Choice Subgame and Noncar Owner Travel Mode Choice Subgame, as shown in Figures 2 and 3. If Nash equilibrium is reached in each of the subgames, the Nash equilibrium of the game is subgame perfect Nash equilibrium, so backward induction is the solution method for obtaining the Nash equilibrium of this game.

(1) Nash Equilibrium of Car Owner Travel Mode Choice Subgame. The key feature of mixed-strategies' Nash equilibrium is that the expectations of the pure strategies are equal; that is, in Car Owner Travel Mode Choice Subgame of Figure 2, the products of the travel mode's payoffs and its probabilities are equal and the sum of their probabilities is 1 , so that

$$
\begin{aligned}
& \mu_{1} R_{\text {car }}^{c}=\mu_{2} R_{\text {taxi }}^{c}=\mu_{3} R_{\text {bus }}^{c}=\mu_{4} R_{\text {rail }}^{c}, \\
& R_{\text {car }}^{c}+R_{\text {taxi }}^{c}+R_{\text {bus }}^{c}+R_{\text {rail }}^{c}=1 .
\end{aligned}
$$

Solving for $R_{\text {car }}^{c}, R_{\text {taxi }}^{c}, R_{\text {bus }}^{c}$, and $R_{\text {rail }}^{c}$, we find

$$
R_{\mathrm{car}}^{c}=\frac{1}{1+\left(\mu_{1} / \mu_{2}\right)+\left(\mu_{1} / \mu_{3}\right)+\left(\mu_{1} / \mu_{4}\right)},
$$

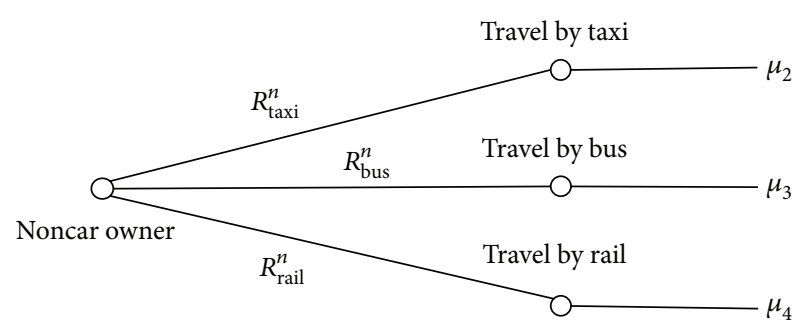

Figure 3: Noncar Owner Travel Mode Choice Subgame.

$$
\begin{aligned}
& R_{\text {taxi }}^{c}=\frac{1}{1+\left(\mu_{2} / \mu_{1}\right)+\left(\mu_{2} / \mu_{3}\right)+\left(\mu_{2} / \mu_{4}\right)}, \\
& R_{\text {bus }}^{c}=\frac{1}{1+\left(\mu_{3} / \mu_{1}\right)+\left(\mu_{3} / \mu_{2}\right)+\left(\mu_{3} / \mu_{4}\right)}, \\
& R_{\text {rail }}^{c}=\frac{1}{1+\left(\mu_{4} / \mu_{1}\right)+\left(\mu_{4} / \mu_{2}\right)+\left(\mu_{4} / \mu_{3}\right)} .
\end{aligned}
$$

The same section is extracted in (2) through (5); hence

$$
A=\frac{1}{\left(1 / \mu_{1}\right)+\left(1 / \mu_{2}\right)+\left(1 / \mu_{3}\right)+\left(1 / \mu_{4}\right)} .
$$

Substituting (6) into (2) through (5), we obtain the simplified values of $R_{\text {car }}^{c}, R_{\text {taxi }}^{c}, R_{\text {bus }}^{c}$, and $R_{\text {rail }}^{c}$ :

$$
\begin{aligned}
& R_{\mathrm{car}}^{c}=\mathrm{A} \frac{1}{\mu_{1}}, \\
& R_{\mathrm{taxi}}^{c}=\mathrm{A} \frac{1}{\mu_{2}}, \\
& R_{\mathrm{bus}}^{c}=\mathrm{A} \frac{1}{\mu_{3}}, \\
& R_{\text {rail }}^{c}=\mathrm{A} \frac{1}{\mu_{4}} .
\end{aligned}
$$

(2) Nash Equilibrium of Noncar Owners Travel Mode Travel Subgame. As with the Car Owner Travel Mode Choice Subgame, in the Noncar Owner Travel Mode Choice Subgame of Figure 3, the products of the travel mode's payoffs and its probabilities are equal and the sum of their probabilities is 1 , so that

$$
\begin{aligned}
\mu_{2} R_{\text {taxi }}^{n} & =\mu_{3} R_{\text {bus }}^{n}=\mu_{4} R_{\text {rail }}^{n}, \\
R_{\text {taxi }}^{n}+R_{\text {bus }}^{n}+R_{\text {rail }}^{n} & =1 .
\end{aligned}
$$

Solving for $R_{\mathrm{taxi}}^{n}, R_{\mathrm{bus}}^{n}$, and $R_{\text {rail }}^{n}$ produces

$$
\begin{aligned}
& R_{\text {taxi }}^{n}=\frac{1}{1+\left(\mu_{2} / \mu_{3}\right)+\left(\mu_{2} / \mu_{4}\right)}, \\
& R_{\text {bus }}^{n}=\frac{1}{1+\left(\mu_{3} / \mu_{2}\right)+\left(\mu_{3} / \mu_{4}\right)}, \\
& R_{\text {rail }}^{n}=\frac{1}{1+\left(\mu_{4} / \mu_{2}\right)+\left(\mu_{4} / \mu_{3}\right)} .
\end{aligned}
$$




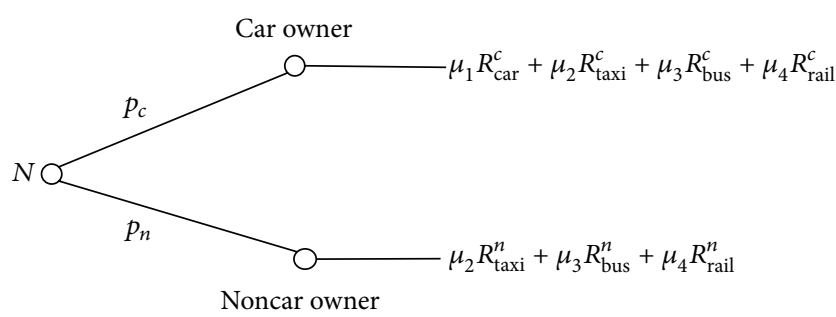

FIgURE 4: Travel mode choice game.

Likewise, extracting the same section in (12) through (14),

$$
B=\frac{1}{\left(1 / \mu_{2}\right)+\left(1 / \mu_{3}\right)+\left(1 / \mu_{4}\right)} .
$$

Simplifying $R_{\text {taxi }}^{n}, R_{\text {bus }}^{n}$, and $R_{\text {rail }}^{n}$ using (15) produces

$$
\begin{aligned}
& R_{\text {taxi }}^{n}=B \frac{1}{\mu_{2}}, \\
& R_{\text {bus }}^{n}=B \frac{1}{\mu_{3}}, \\
& R_{\text {rail }}^{n}=B \frac{1}{\mu_{4}} .
\end{aligned}
$$

(3) Nash Equilibrium of Travel Mode Choice Game. The payoffs of the car owner and the noncar owner are their overall expectations described by Figure 4. Similarly, the products of the payoffs and probabilities are equal and the sum of their probabilities is one, so

$$
\begin{aligned}
& {\left[\mu_{2} R_{\text {taxi }}^{n}+\mu_{3} R_{\text {bus }}^{n}+\mu_{4} R_{\text {rail }}^{n}\right] \cdot p_{n}} \\
& \quad=\left[\mu_{1} R_{\text {car }}^{c}+\mu_{2} R_{\text {taxi }}^{c}+\mu_{3} R_{\text {bus }}^{c}+\mu_{4} R_{\text {rail }}^{c}\right] \cdot p_{c}, \\
& p_{c}+p_{n}=1 .
\end{aligned}
$$

Solve for $p_{c}$ and $p_{n}$; that is,

$p_{c}$

$$
=\frac{\mu_{2} R_{\text {taxi }}^{n}+\mu_{3} R_{\text {bus }}^{n}+\mu_{4} R_{\text {rail }}^{n}}{\mu_{1} R_{\text {car }}^{c}+\mu_{2} R_{\text {taxi }}^{c}+\mu_{3} R_{\text {bus }}^{c}+\mu_{4} R_{\text {rail }}^{c}+\mu_{2} R_{\text {taxi }}^{n}+\mu_{3} R_{\text {bus }}^{n}+\mu_{4} R_{\text {rail }}^{n}},
$$

$p_{n}$

$$
=\frac{\mu_{1} R_{\text {car }}^{c}+\mu_{2} R_{\text {taxi }}^{c}+\mu_{3} R_{\text {bus }}^{c}+\mu_{4} R_{\text {rail }}^{c}}{\mu_{1} R_{\text {car }}^{c}+\mu_{2} R_{\text {taxi }}^{c}+\mu_{3} R_{\text {bus }}^{c}+\mu_{4} R_{\text {rail }}^{c}+\mu_{2} R_{\text {taxi }}^{n}+\mu_{3} R_{\text {bus }}^{n}+\mu_{4} R_{\text {rail }}^{n}} .
$$

Simplify the $p_{c}$ and $p_{n}$ by (6) and (15); that is,

$$
\begin{aligned}
& p_{c}=\frac{3 B}{4 A+3 B}, \\
& p_{n}=\frac{4 A}{4 A+3 B} .
\end{aligned}
$$

Let $R_{\text {car }}$ denote the proportion of travel by car for the overall traveler, $R_{\text {taxi }}$ by taxi, $R_{\text {bus }}$ by bus, and $R_{\text {rail }}$ by rail. The following equations are the result:

$$
R_{\text {car }}=p_{c} R_{\text {car }}^{c}
$$

$$
\begin{aligned}
& R_{\mathrm{taxi}}=p_{c} R_{\mathrm{taxi}}^{c}+p_{n} R_{\mathrm{taxi}}^{n}, \\
& R_{\text {bus }}=p_{c} R_{\text {bus }}^{c}+p_{n} R_{\text {bus }}^{n}, \\
& R_{\text {rail }}=p_{c} R_{\text {rail }}^{c}+p_{n} R_{\text {rail }}^{n} .
\end{aligned}
$$

Substituting (7) through (10), (16) through (18), and (22) through (23) into (24) through (27), we find

$$
\begin{aligned}
& R_{\text {car }}=3 \cdot \frac{A B}{4 A+3 B} \cdot \frac{1}{\mu_{1}}, \\
& R_{\text {taxi }}=7 \cdot \frac{A B}{4 A+3 B} \cdot \frac{1}{\mu_{2}}, \\
& R_{\text {bus }}=7 \cdot \frac{A B}{4 A+3 B} \cdot \frac{1}{\mu_{3}}, \\
& R_{\text {rail }}=7 \cdot \frac{A B}{4 A+3 B} \cdot \frac{1}{\mu_{4}} .
\end{aligned}
$$

Equations (24) through (27), or (28) through (31), represent the Nash equilibrium of the travel mode choice game, a structure of travel mode choice. Obviously, for a given travel mode, there is a strong negative relationship between the proportion of an inhabitant and its payoff. That is, as its payoff is increasing, the proportion is decreasing. However, the same section of (28) through (31) implies that there is some relationship between the proportion and the payoffs of all the travel modes; this will be analyzed in the next section.

\section{Model Sensitivity Analysis}

The purpose of sensitivity analysis is to dissect the relationships between the payoff in travelling via the various modes and their proportions in an urban transport system. The change in transport cost has a direct relationship with the improvement of transportation infrastructure and the execution of transport policy. For example, Chinese cities are at this time rapidly building a lot of urban rail transit capability to alleviate traffic congestion.

To analyze the evolution of travel mode choice, assume that the payoff in travelling by rail $\left(\mu_{4}\right)$ is variable but that the other payoffs $\left(\mu_{1}, \mu_{2}\right.$, and $\left.\mu_{3}\right)$ are constant and that the same section of (28) through (31) can represent a function with $\mu_{4}$ variable and that is $\varphi\left(\mu_{4}\right)=A B / 4 A+3 B$. Obviously, in this situation the functions of travel by car, taxi, and bus with $\mu_{4}$ variable, that is, $R_{\text {car }}\left(\mu_{4}\right), R_{\text {taxi }}\left(\mu_{4}\right)$, and $R_{\text {bus }}\left(\mu_{4}\right)$, have exclusive and positive relationships with $\varphi\left(\mu_{4}\right)$, and the function of travel by rail, $R_{\text {rail }}\left(\mu_{4}\right)$, is the joint effect of $\varphi\left(\mu_{4}\right)$ and $\mu_{4}$.

(a) Analyzing the Tendency of Travel by Car, by Bus, and by Taxi. After (6) and (15) are substituted into $\varphi\left(\mu_{4}\right)$, take the derivative of the $\varphi\left(\mu_{4}\right)$ with respect to $\mu_{4}$, producing 


$$
\varphi^{\prime}\left(\mu_{4}\right)=\frac{7}{\left(\left(4 /\left(1 / \mu_{2}\right)+\left(1 / \mu_{3}\right)\right)+\left(3 /\left(1 / \mu_{1}\right)+\left(1 / \mu_{2}\right)+\left(1 / \mu_{3}\right)\right)+\left(1 / \mu_{4}\right)\right)^{2} \cdot \mu_{4}^{2}} .
$$

It is apparent that the first derivative of $\varphi\left(\mu_{4}\right)$ is greater than zero and that the value of $\varphi\left(\mu_{4}\right)$ increases with $\mu_{4}$. It is therefore confirmed that the functions $R_{\text {car }}\left(\mu_{4}\right), R_{\text {taxi }}\left(\mu_{4}\right)$, and $R_{\text {bus }}\left(\mu_{4}\right)$ are monotonically increasing functions of $\mu_{4}$, and while their payoffs are diminished the proportions of travel by car, by bus, and by taxi will be reduced.

(b) Analyzing the Tendency of Travel by Rail. Take the derivative of $R_{\text {rail }}\left(\mu_{4}\right)$ with respect to $\mu_{4}$, yielding

$$
\begin{aligned}
R_{\text {rail }}^{\prime}\left(\mu_{4}\right)= & -7 \cdot \frac{1}{\mu_{4}} \\
& \cdot \frac{\left(3 / \mu_{1}\right)+\left(7 / \mu_{2}\right)+\left(7 / \mu_{3}\right)}{\left(\left(3 / \mu_{1}\right)+\left(7 / \mu_{2}\right)+\left(7 / \mu_{3}\right)+\left(7 / \mu_{4}\right)\right)^{2}}
\end{aligned}
$$

The first derivative of $R_{\text {rail }}\left(\mu_{4}\right)$ is less than zero, and it is a monotonically decreasing function of $\mu_{4}$. That is, while the payoff of travel by rail reduces, its proportion will rise.

In conclusion, the payoff reduction of travel by rail will result in a rising proportion of travel by rail, and, for the falling proportions of travel by other modes, the converse will be true. In a similar way, the payoff changes for travel by car, by bus, and by taxi have similar consequences.

As expected, the sensitivity analysis demonstrates that the model is capable of capturing the evolutionary process of inhabitants' travel mode choice.

\section{Model Application Analysis}

5.1. Application Scope and Condition of the Model. In this section, the application scope and condition of the model is illustrated.

(1) Application Scope. The model provides the method and basis for analyzing evolution process and its affecting factors of a structure of travel mode choice, and the crux of using this model is how to establish a correct payoff function. Payoff function is a tie between structure of travel mode choice and the affecting factors determined by study purpose. The payoff function of application example mentioned below employs two direct variables: travel time and travelling expense, which are inhabitant's uppermost concern. Meanwhile, they are joint effects of affecting factors such as traffic congestion, the choice of route, and transport policy. If a certain factor is a key for consideration, the approach is to build a payoff function with travel time and travelling expense as intermediate variables; for instance, impact of traffic congestion on travel mode choice is analyzed below.

Payoff function, certainly, is able to own abundant connotations. If payoff function is related to a tendency of route choice, disparate answers can be attained on different bases of route choice principle such as the least travel time, the shortest travel distance, and dynamic route choice, because a travel is a result of inhabitant travel mode choice and route choice. If the carbon emission is emphasized, it is essential that a payoff function related to carbon emission indicators is built. Provided a payoff function exists and is real, the evolution game model of travel mode choice can play an efficient role.

(2) Application Condition. As evolutionary game theory focuses on dynamic equilibrium, the Nash equilibrium of the model is dynamically determined based on context variation, and the dynamical equilibrium will delay in responding to context changes. When context variation happens, irrational inhabitants repeatedly game because of information shortage, and they will recover through the collection, procession, and feedback of traffic information. If frequent context variation leads to players' irrationality status continuing, it goes against the bounded-rationality characteristic of evolution game. So, this model cannot analyze the real time evolution of travelmode choice structure as transport context varies.

The "delay gratification" of the model confirms the demand for time spent by transport polices and transport construction projects to achieve the best results. The traffic has fast growth in the initial operation of new lines and gradually reaches stabilization, and transport policies, such as fare adjustment, have the most impact on inhabitant travel at the initial stage of its implementation. So the model is able to analyze the long-term complex influence of travel mode choice processes on transport policies and transport construction projects.

5.2. Model Application Example. In this section, the model is applied to the city of Beijing during morning peak hours.

(1) Data Source. Travel choices of 2141 inhabitants traveling during the morning peak hours were sampled and the following data collected by questioning them and querying the resulting database from the Internet.

(a) Origin and Destination Position and Their Travel Mode Choice. Since the travels directed at going to work or to school during morning peak hours represented absolute necessity, the process, time, and fare were comparatively stationary. The survey program used the method of cluster sampling and inhabitants with various professions such as civil servants, salespersons, engineers, and workers from the 152 government offices or corporations in Beijing's 9 regions were sampled and investigated using questionnaires. At the very least their origin and destination position and most frequent travel modes were noted.

(b) Travel Strategies, Travel Time, and Travelling Expense of the Origin and Destination Position. The electric maps online 
afforded access to alternative travel modes, transfer strategies, expected time, and expense to the traveling inhabitants; trip convenience was the reference sources for these data in the paper.

(2) Payoff Function. Survey data showed that travel cost paid by inhabitants was the principal motive power of their travel mode choice. Generalized travel costs included the travel time and the travelling expense. During morning peak hours, 92.5 percent of inhabitants regarded the stability of travel time as the main basis for their travel mode choice, and 78.5 percent made it clear that they had a limited budget for travel. Therefore, the payoff of inhabitant travel was viewed from two aspects: travel time and travelling expense.

(a) Travel Time. The concept of travel time can be defined as the time elapsed when a traveler transits between two distinct spatial positions and is applicable to any transportation mode (or combinations of modes) regardless of the inherent differences across them [42].

In road networks, travel time may be split into two components: free-flow time and additional time. The former refers to the amount of time it takes a driver to arrive at his/hers destination in light traffic; the latter refers to each increase of travel time due to variations in traffic conditions. These variations may be predictable (e.g., peakhour congestion) or unpredictable (e.g., vehicular crashes). Peak-hour congestion is to be expected by travelers, and thus travelers perform the necessary adjustments to offset the added costs, like departing earlier to avoid arriving late to work. Unpredictable variations, like vehicular crashes, link directly to the uncertainty of travel time. Nevertheless, such uncertainty will be considered negligible as an exceptional case in an infinitely repeated game.

Travel time by public transit tends to be divided into waiting time, in-vehicle time, transfer time, and walking time. For bus and taxi, the waiting time and the in-vehicle time are bound up with the vehicle speed in road networks, and congestion might prolong their travel time indefinitely. For rail transit, there is little variation in travel time due to road traffic conditions, and its elasticity is not materially different from conventional contexts [43]. However, the transfer time and the walking time in the rail situation reflect the network coverage of the public transport system and collaboration among transport subsystems.

Travel time was therefore a performance composite indicator of the urban transport system and the strongest predictor of mode choice [44].

(b) Travelling Expense. Although stability of travel time is the overriding factor in choosing a travel mode during peak hours, limited memory tends to impair travelers' rationality [45]. Therefore, adjusting the travelling expense has been the favored means of relieving traffic congestion. Measures like traffic congestion toll, fuel tax, parking fees, and automobile acquisition taxi have been implemented to restricting both car ownership and their car trip frequency.

(c) Payoff Function. A traveler should optimize a given trip by choosing the best combination of expected travel times and monetary costs. The travel time and the travelling expenses are independent of one another, and their functions are only differentiated in degree and not essentially. Only when their values are simultaneously the lowest will the payoff be the minimum. If one of them is not the lowest, the payoff will be higher. So the payoff can be analyzed through examining their product.

Car, taxi, bus, and rail's average travel time are represented symbolically by $T_{\text {car }}, T_{\text {taxi }}, T_{\text {bus }}$, and $T_{\text {rail }}$, and their average travelling expense is represented by $F_{\text {car }}, F_{\text {taxi }}, F_{\text {bus }}$, and $F_{\text {rail }}$. Then their payoff functions can be expressed by the following equations:

$$
\begin{aligned}
& f_{\text {car }}=\pi_{1}=T_{\text {car }} F_{\text {car }}, \\
& f_{\text {taxi }}=\pi_{2}=T_{\text {taxi }} F_{\text {taxi }}, \\
& f_{\text {bus }}=\pi_{3}=T_{\text {bus }} F_{\text {bus }}, \\
& f_{\text {rail }}=\pi_{4}=T_{\text {rail }} F_{\text {rail }} .
\end{aligned}
$$

(3) Nash Equilibrium of Travel Mode Choice Evolutionary Game in Beijing. 418 samples with origins and destinations within one kilometer to rail station were chosen from among the total of 2141 Beijing samples; that is, these inhabitants could carry out their travel plan by a singular travel mode (by bus or by rail), rather than by transfer between one and another. Meanwhile, the choice of travel route follows the principle of the least travel time. If we average across travel time and travelling expense, substitute the result into (34) through (37), and calculate the payoff values, we can arrive at Nash equilibrium using (28) through (31), as shown in Table 1. Among these values, the travelling expense by car included fuel and parking costs and was assigned an approximate one RMB based on the survey data.

When the structure of travel mode choice reaches the Nash equilibrium values of Table 1 , an inhabitant's travel mode will remain stationary unless the payoffs of one or more modes are changed. If a mode violates this stationary condition, the greater payoffs will be paid out by him/her or someone else and a small perturbation will appear. Then Nash equilibrium will be reached again after self-adaptive adjusting.

The reason for the difference between the Nash equilibriums of the model and the survey results in Table 1 is the stochastic nature of a transport system that causes a payoff change and makes a travel mode choice fluctuate. Because travel time and travelling expense codetermine the payoff value, stochastic elements like the weather and traffic conditions can delay their change and cause them to vary. In bad weather, inhabitants favor travel by rail because of controllable time; when traffic information is sufficiently provided, inhabitants may favor driving because of convenience and comfort. The survey data showed that $51.2 \%$ of travelers would consider changing their travel mode in the case of unexpected random events and $78.1 \%$ of car owners would travel by rail in the roughest weather.

(4) Impact of Traffic Congestion on Travel Mode Choice. The data in Table 1 represent the Beijing morning peak-hour 
TABLE 1: Nash equilibrium of travel mode choice game in Beijing.

\begin{tabular}{lccccc}
\hline Travel mode & Average travel time & Average travelling expense & Payoff value & Nash equilibrium & Survey result \\
\hline Car & 32.55 & 13.41 & 218.25 & 321.11 & 0.24 \\
Bus & 84.95 & 3.78 & 1563.30 & 0.32 & 0.27 \\
Taxi & 40.26 & 38.83 & 274.64 & 0.07 & 0.29 \\
Rail & 60.36 & 4.55 & 0.37 & 0.05 \\
\hline
\end{tabular}

traffic state, during which the Traffic Performance Index is 7.5 and the Regional Average Speed is 24.5 kilometers per hour. This section will discuss the impact of the Traffic Performance Index.

Originating in Beijing, the Traffic Performance Index, or TPI for short, is a conceptual value reflecting whether the road network is unimpeded or crowded. The parameter is obtained by meticulously processing dynamic position data of the vehicles located in avenues and alleys in cities. First, it considers vehicle speeds on different classes of road based on the vehicle position; then the class weights consider each road's function and traffic flow; then the value of TPI is converted into a congestion index ranging from 0 to 10 ; the conversion is made by people experienced in perceiving and judging traffic congestion. The TPI index is divided into 5 different grades in order, smallest to largest in value, corresponding to five traffic states: unimpeded, relatively unimpeded, mildly crowded, moderately crowded, and severely crowded.

The TPI is a synthetic indicator aggregating vehicle speed, road grade, and peoples' perceptions, but its relationship with travel time and travelling expense will be a focus of this paper.

(a) TPI and Travel Time. According to the data from the TPI and Regional Average Speed $(V)$ published by the Beijing Municipal Commission of Transport, regression was performed using the TPI as an independent variable and Regional Average Speed $(V)$ as a dependent variable. Figure 5 reveals a strong correlation between the two, and the univariate cubic given in (38) is their regression result:

$$
\begin{aligned}
V(\mathrm{TPI})= & 52.175-10.858 \mathrm{TPI}+1.713 \mathrm{TPI}^{2} \\
& -0.101 \mathrm{TPI}^{3} \\
R^{2}= & 0.914 .
\end{aligned}
$$

If we use the traffic state shown by the data in Table 1 as reference, assume that the relationship between the waiting time and the Regional Average Speed of the bus or taxi is equal to the relationship between the in-vehicle time and their speeds are the same, and neglect the impact of walking time; the travel time adjustment coefficient $\Delta_{1}$ is expressed in the following:

$$
\Delta_{1}=\frac{T(\mathrm{TPI})}{T(7.5)}=\frac{V(7.5)}{V(\mathrm{TPI})} .
$$

(b) TPI and Travelling Expense. Traffic congestion causes travel time by all travel modes except rail to increase and this increase is due not only to the in-vehicle time but also to

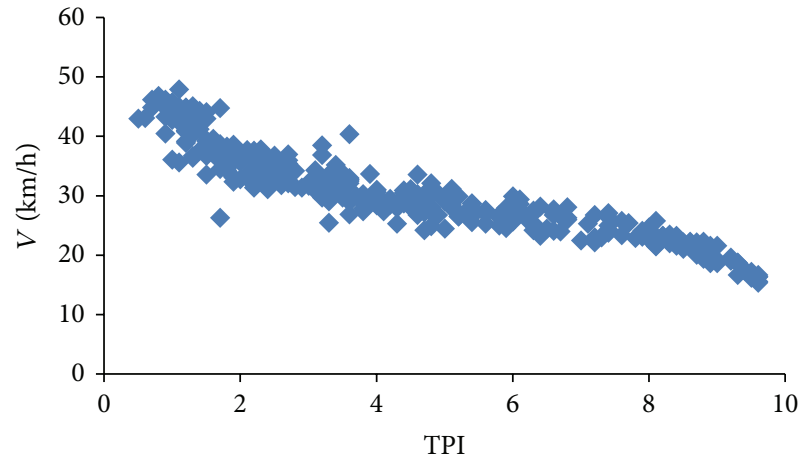

FIGURE 5: Scatter plot for relationship between TPI and Regional Average Speed.

waiting time for buses and taxis. It also has a significant effect on travelling expense by taxi because of delay surcharges in Beijing. That is, the travelling expense by bus experiences almost no chance, and the extra spending brought on the lower speed is not taken into account by the car owner. Thus only travelling expense for taxi travel needs adjustment, and the adjusted travelling expense for taxi is expressed in (40) including the travel time adjustment coefficient $\Delta_{1}$ :

$$
F_{\text {taxi }}(\mathrm{TPI})=F_{\text {taxi }}(7.5)+\left(\Delta_{1}-1\right) \cdot T(\mathrm{TPI}) \cdot f_{d},
$$

where $f_{d}=$ average delay surcharges per kilometer and $f_{d}=1$ in Beijing according to the survey data.

(c) TPI and the Nash Equilibrium. To describe the change process of travel mode choice, calculation steps of 0.5 will be used over the range of TPI values. Adjusting the average travel time and average travelling expense in Table 1 by (39) and (40), the 21 sets of data, in which the Nash equilibrium of the game corresponds to the TPI, are listed in Table 2. The changing trend graph for four travel mode choice charts are shown in Figure 6.

As can be seen in Figure 6, there is a difference among the changing trends of the four travel modes.

The proportion of inhabitants travelling by car decreases as the value of TPI increases, while the trends of travel by bus and by taxi are the same. In each case the proportion of inhabitants travelling by taxi is far below those travelling by car or by bus, and it experiences the largest drop in the unimpeded and relatively unimpeded traffic states and the smallest drop in the mildly crowded state, an obvious result of executing delay surcharges. Overall, the proportion of travel by car is less than that for travel by bus, and both of them have accelerated reduction when the value of TPI is greater than 7.5. 
TABLE 2: Nash equilibrium of travel mode choice game under the TPIs.

\begin{tabular}{|c|c|c|c|c|}
\hline TPI & Proportion of travel by car & Proportion of travel by bus & Proportion of travel by taxi & Proportion of travel by rail \\
\hline 0 & 0.270 & 0.373 & 0.155 & 0.202 \\
\hline 0.5 & 0.269 & 0.372 & 0.136 & 0.223 \\
\hline 1 & 0.266 & 0.367 & 0.126 & 0.242 \\
\hline 1.5 & 0.263 & 0.363 & 0.114 & 0.260 \\
\hline 2 & 0.260 & 0.359 & 0.104 & 0.277 \\
\hline 2.5 & 0.256 & 0.354 & 0.096 & 0.293 \\
\hline 3 & 0.254 & 0.350 & 0.090 & 0.306 \\
\hline 3.5 & 0.251 & 0.347 & 0.085 & 0.317 \\
\hline 4 & 0.249 & 0.343 & 0.081 & 0.327 \\
\hline 4.5 & 0.247 & 0.341 & 0.078 & 0.334 \\
\hline 5 & 0.245 & 0.339 & 0.076 & 0.340 \\
\hline 5.5 & 0.244 & 0.337 & 0.074 & 0.346 \\
\hline 6 & 0.242 & 0.335 & 0.072 & 0.352 \\
\hline 6.5 & 0.241 & 0.332 & 0.069 & 0.358 \\
\hline 7 & 0.238 & 0.329 & 0.067 & 0.365 \\
\hline 7.5 & 0.236 & 0.326 & 0.063 & 0.375 \\
\hline 8 & 0.232 & 0.320 & 0.059 & 0.389 \\
\hline 8.5 & 0.226 & 0.312 & 0.054 & 0.408 \\
\hline 9 & 0.218 & 0.301 & 0.047 & 0.434 \\
\hline 9.5 & 0.206 & 0.284 & 0.039 & 0.471 \\
\hline 10 & 0.187 & 0.259 & 0.029 & 0.526 \\
\hline
\end{tabular}

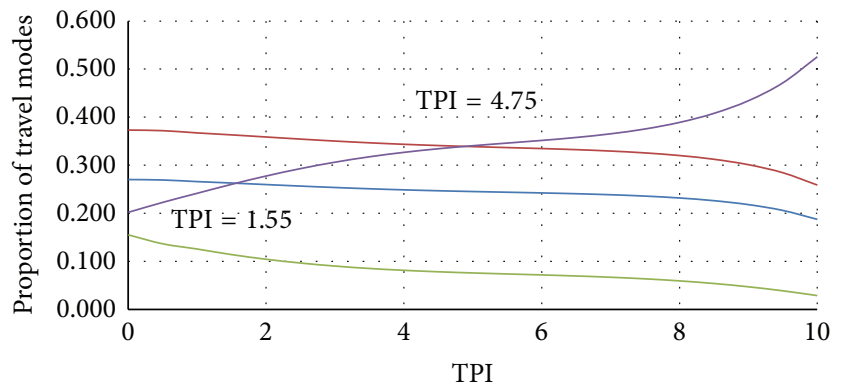

_ Proportion of travel by car

_ Proportion of travel by taxi

_ Proportion of travel by bus

_ Proportion of travel by rail

Figure 6: Changing trends of choice among four travel modes.

The proportion of inhabitants travelling by rail is a monotonically increasing function of TPI, the trend line of travel by rail intersects the line of by car at the point where the TPI equals 1.55, and it intersects the line of by bus at the point where the TPI equals 4.75 . The proportion of travel by rail is less than travel by car when the value of the TPI is less than 1.55 and is greater than travel by bus when the TPI value is greater than 4.75 . That is, in the unimpeded traffic state, the inhabitants generally tend to choose travel by bus or by car because of shorter walking time and more flexible options. As the flow increases on the road network, the number of inhabitants choosing travel by rail continues to increase. When the road network begins to become crowded, the urban public transit system constituted by combined rail and bus slowly accounts for more and more actual trips (a minimum of $65 \%$ ). The more severe the urban traffic congestion is, the more the inhabitants are inclined toward rail transit because of the independence of the road network. This tendency will be much clearer as the value of TPI increases. This confirms that fast construction of the urban rail transit should be an effective means of alleviating traffic congestion.

\section{Conclusions}

This paper has compared the characteristics of an evolution game to the process of inhabitant travel mode choice and has created a two-stage model representing inhabitant travel mode choice. The model is based on the following premises: (1) mixed strategies are used during inhabitant travelling, so the probabilities of inhabitants travelling by these modes are the likely composition of urban transportation; (2) the samples are the inhabitants travelling at the same time; (3) the strategy set concludes four modes: car, taxi, bus, and rail, a key consideration for those who often engage in long-distance travel.

The Nash equilibrium of travel mode choice game embodies a relationship between the structure of travel mode choice and payoffs of travel modes. Model sensitivity analysis has concluded that the payoff reduction of travel by any mode will result in a rising proportion of inhabitants travelling using this mode and falling proportions of inhabitants travelling by other modes. Obviously, the payoff change is the result of context variation; a combination of travel mode payoffs corresponds to a Nash equilibrium; the change curve of the 
Nash equilibrium is then the evolution process of travel mode choice. The crux of using this model to analyze the evolution process under the unstable context is the way in which the payoff function synthetically reflects the environmental factors.

When the model estimates the structure of travel mode choice during Beijing morning peak hours, the payoff function is the product of the average travel time and the average travelling expense, comprehensively embodying individual sociodemographic factors, intention factors, and travel context factors. Based on the relationship between the traffic states and the payoffs established through the TPI, the change tendency of the structure of travel modes under the traffic congestion context should produce a tendency diagram like that of Figure 6. Similarly, when an institutional transportation policy, such as adjusting the public transit fare, adding a new metro line, or instituting a traffic control measure, is implemented, how will the pattern of travel mode choice change? The evolution game mode of travel mode choice can help answer this question.

However, the strategies of the game model are based on pure transportation modes, and combined modes are very common. For example, a sizable proportion of inhabitants transfers between rail and bus, especially in cases of lower coverage by the urban rail network, and some people travel by combined car and public transit under the burdens of traffic congestion toll in urban centers and the high parking fees during peak hours. This model obviously cannot resolve combined transportation modes, so this represents a direction for future work.

\section{Conflict of Interests}

The authors declare that there is no conflict of interests regarding the publication of this paper.

\section{Acknowledgment}

This work was partially supported by National Natural Science Foundation of China (Project no. 51278158).

\section{References}

[1] R. Jago, L. Wood, S. J. Sebire et al., "School travel mode, parenting practices and physical activity among UK Year 5 and 6 children," BMC Public Health, vol. 14, no. 1, article 370, 2014.

[2] S. Kim and G. F. Ulfarsson, "Travel mode choice of the elderly: effects of personal, household, neighborhood, and trip characteristics," Transportation Research Record, vol. 1894, no. 1, pp. 117-126, 2004.

[3] E. Matthies, S. Kuhn, and C. A. Klöckner, "Travel mode choice of women: the result of limitation, ecological norm, or weak habit?" Environment \& Behavior, vol. 34, no. 2, pp. 163-177, 2002.

[4] N. Murtagh, B. Gatersleben, and D. Uzzell, "Multiple identities and travel mode choice for regular journeys," Transportation Research Part F: Traffic Psychology and Behaviour, vol. 15, no. 5, pp. 514-524, 2012.
[5] A. K. Yarlagadda and S. Srinivasan, "Modeling children's school travel mode and parental escort decisions," Transportation, vol. 35, no. 2, pp. 201-218, 2008.

[6] E. Mann and C. Abraham, "The role of affect in UK commuters' travel mode choices: an interpretative phenomenological analysis," British Journal of Psychology, vol. 97, no. 2, pp. 155-176, 2006.

[7] Y. O. Susilo, N. Hanks, and M. Ullah, "An exploration of shoppers travel mode choice in visiting convenience stores in the UK," Transportation Planning and Technology, vol. 36, no. 8, pp. 669-684, 2013.

[8] E. J. Miller, M. J. Roorda, and J. A. Carrasco, "A tour-based model of travel mode choice," Transportation, vol. 32, no. 4, pp. 399-422, 2005.

[9] E. Mann and C. Abraham, "Identifying beliefs and cognitions underpinning commuters' travel mode choices," Journal of Applied Social Psychology, vol. 42, no. 11, pp. 2730-2757, 2012.

[10] A. Nordlund and K. Westin, "Influence of values, beliefs, and age on intention to travel by a new railway line under construction in northern Sweden," Transportation Research Part A: Policy and Practice, vol. 48, pp. 86-95, 2013.

[11] J. De Vos, P. Mokhtarian, T. Schwanen et al., "Travel mode choice and travel satisfaction: bridging the gap between decision utility and experienced utility," in Proceedings of the World Symposium on Transport and Land Use Research, Delft, The Netherlands, June 2014.

[12] B. Gatersleben, N. Murtagh, and E. White, "Hoody, goody or buddy? How travel mode affects social perceptions in urban neighbourhoods," Transportation Research Part F: Traffic Psychology and Behaviour, vol. 21, pp. 219-230, 2013.

[13] A. Mortazavi, K. Singa, X. Pan et al., "Effect of real time information on commuter travel mode," in Proceedings of the Transportation Research Board 90th Annual Meeting, Washington, DC, USA, January 2011.

[14] R. Mitra, R. N. Buliung, and M. J. Roorda, "Built environment and school travel mode choice in Toronto, Canada," Transportation Research Record, vol. 2156, no. 1, pp. 150-159, 2010.

[15] S. Pike, "Travel mode choice and social and spatial reference groups," Transportation Research Record, vol. 2412, no. 1, pp. 75$81,2014$.

[16] A. de Nazelle, S. Fruin, D. Westerdahl et al., "A travel mode comparison of commuters' exposures to air pollutants in Barcelona," Atmospheric Environment, vol. 59, pp. 151-159, 2012.

[17] D. J. Briggs, K. de Hoogh, C. Morris, and J. Gulliver, "Effects of travel mode on exposures to particulate air pollution," Environment International, vol. 34, no. 1, pp. 12-22, 2008.

[18] B. Verplanken, H. Aarts, A. Knippenberg, and C. Knippenberg, "Attitude versus general habit: antecedents of travel mode choice," Journal of Applied Social Psychology, vol. 24, no. 4, pp. 285-300, 1994

[19] T. Friedrichsmeier, E. Matthies, and C. A. Klöckner, "Explaining stability in travel mode choice: an empirical comparison of two concepts of habit," Transportation Research Part F: Traffic Psychology and Behaviour, vol. 16, pp. 1-13, 2013.

[20] B. Gardner, "Modelling motivation and habit in stable travel mode contexts," Transportation Research Part F: Traffic Psychology and Behaviour, vol. 12, no. 1, pp. 68-76, 2009.

[21] B. Verplanken, I. Walker, A. Davis, and M. Jurasek, "Context change and travel mode choice: combining the habit discontinuity and self-activation hypotheses," Journal of Environmental Psychology, vol. 28, no. 2, pp. 121-127, 2008. 
[22] C. Xiong, X. Chen, X. He, W. Guo, and L. Zhang, "The analysis of dynamic travel mode choice: a heterogeneous hidden Markov approach," in Proceedings of the 94th Annual Meeting of Transportation Research Board, Washington, DC, USA, January 2015.

[23] N. Coulombel and A. De Palma, "Variability of travel time, congestion, and the cost of travel," Mathematical Population Studies, vol. 21, no. 4, pp. 220-242, 2014.

[24] Z. Cui, Z. X. Gan, and X. Xie, "Nash equilibrium analysis based on a generalized travel cost," in Applied Mechanics and Materials, pp. 2205-2212, Trans Tech Publications, 2014.

[25] M. Oliveira, P. Vovsha, J. Wolf et al., "GPS-assisted prompted recall household travel survey to support development of advanced travel model in Jerusalem, Israel," in Proceedings of the Transportation Research Board 90th Annual Meeting, Washington, DC, USA, January 2011.

[26] H. Gong, C. Chen, E. Bialostozky, and C. T. Lawson, "A GPS/GIS method for travel mode detection in New York City," Computers, Environment and Urban Systems, vol. 36, no. 2, pp. 131-139, 2012.

[27] M. Paulssen, D. Temme, A. Vij, and J. L. Walker, "Values, attitudes and travel behavior: a hierarchical latent variable mixed logit model of travel mode choice," Transportation, vol. 41, no. 4, pp. 873-888, 2014.

[28] C. A. Klöckner and T. Friedrichsmeier, "A multi-level approach to travel mode choice-how person characteristics and situation specific aspects determine car use in a student sample," Transportation Research Part F: Traffic Psychology and Behaviour, vol. 14, no. 4, pp. 261-277, 2011.

[29] H. Omrani, O. Charif, P. Gerber, A. Awasthi, and P. Trigano, "Prediction of individual travel mode with evidential neural network model," Transportation Research Record, vol. 2399, no. 1, pp. 1-8, 2013.

[30] Y. Hollander and J. N. Prashker, "The applicability of noncooperative game theory in transport analysis," Transportation, vol. 33, no. 5, pp. 481-496, 2006.

[31] G. Laporte, J. A. Mesa, and F. Perea, "A game theoretic framework for the robust railway transit network design problem," Transportation Research Part B: Methodological, vol. 44, no. 4, pp. 447-459, 2010.

[32] M. G. H. Bell, U. Kanturska, J.-D. Schmöcker, and A. Fonzone, "Attacker-defender models and road network vulnerability," Philosophical Transactions of the Royal Society A: Mathematical, Physical and Engineering Sciences, vol. 366, no. 1872, pp. 18931906, 2008.

[33] A. Reilly, L. Nozick, N. X. Xu, and D. Jones, "Game theorybased identification of facility use restrictions for the movement of hazardous materials under terrorist threat," Transportation Research Part E: Logistics and Transportation Review, vol. 48, no. 1, pp. 115-131, 2012.

[34] M. E. Koryagin, "Competition of public transport flows," Automation and Remote Control, vol. 69, no. 8, pp. 1380-1389, 2008.

[35] M. Ishii, P. T.-W. Lee, K. Tezuka, and Y.-T. Chang, "A game theoretical analysis of port competition," Transportation Research Part E: Logistics and Transportation Review, vol. 49, no. 1, pp. 92-106, 2013.

[36] A. Rahman, N. E. Lownes, J. N. Ivan, L. Fiondella, S. Rajasekaran, and R. Ammar, "A game theory approach to identify alternative regulatory frameworks for hazardous materials routing," in Proceedings of the 12th IEEE International
Conference on Technologies for Homeland Security (HST '12), pp. 489-494, IEEE, Waltham, Mass, USA, November 2012.

[37] Y. Dadkar, L. Nozick, and D. Jones, "Routing of hazardous material shipments under the threat of terrorist attack," in Security and Environmental Sustainability of Multimodal Transport, M. G. H. Bell, S. H. Hosseinloo, and U. Kanturska, Eds., pp. 89-110, Springer, Dordrecht, The Netherlands, 2010.

[38] X. G. Chen and Z. Jing, Evolutionary Game Theory Analysis of the Travel Mode Choice of Urban Traveler, Science Press, Beijing, China, 2007.

[39] B. Chidambaram, M. A. Janssen, J. Rommel, and D. Zikos, "Commuters' mode choice as a coordination problem: a framed field experiment on traffic policy in Hyderabad, India," Transportation Research Part A: Policy and Practice, vol. 65, pp. 9-22, 2014.

[40] L. Smith, "Folk theorems in overlapping generations games," Games and Economic Behavior, vol. 4, no. 3, pp. 426-449, 1992.

[41] J. Ratliff, "A folk theorem sampler," Great Introductory Notes to the Folk Theorem, pp. 1-34, 1996, http://www.virtualperfection .com/gametheory.

[42] C. Carrion and D. Levinson, "Value of travel time reliability: a review of current evidence," Transportation Research Part A: Policy and Practice, vol. 46, no. 4, pp. 720-741, 2012.

[43] M. Wardman, "Review and meta-analysis of U.K. time elasticities of travel demand," Transportation, vol. 39, no. 3, pp. 465490, 2012.

[44] L. Frank, M. Bradley, S. Kavage, J. Chapman, and T. K. Lawton, "Urban form, travel time, and cost relationships with tour complexity and mode choice," Transportation, vol. 35, no. 1, pp. 37-54, 2008.

[45] A. Innocenti, P. Lattarulo, and M. G. Pazienza, "Car stickiness: heuristics and biases in travel choice," Transport Policy, vol. 25, pp. 158-168, 2013. 


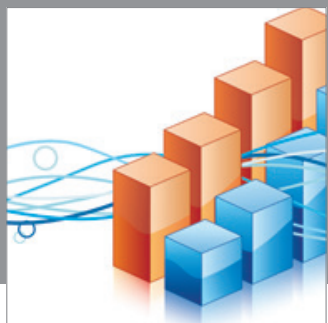

Advances in

Operations Research

mansans

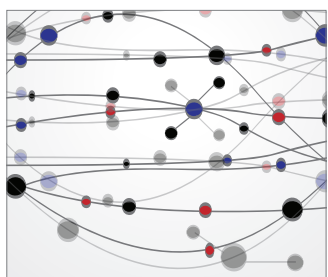

The Scientific World Journal
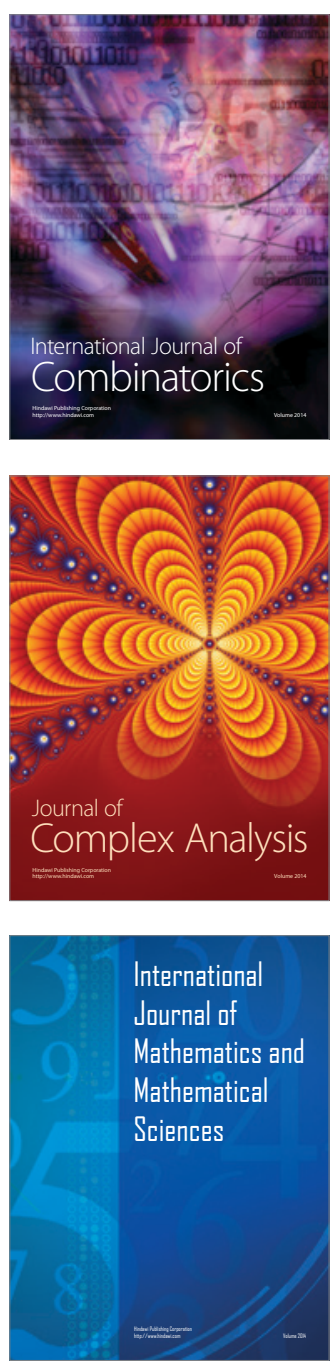
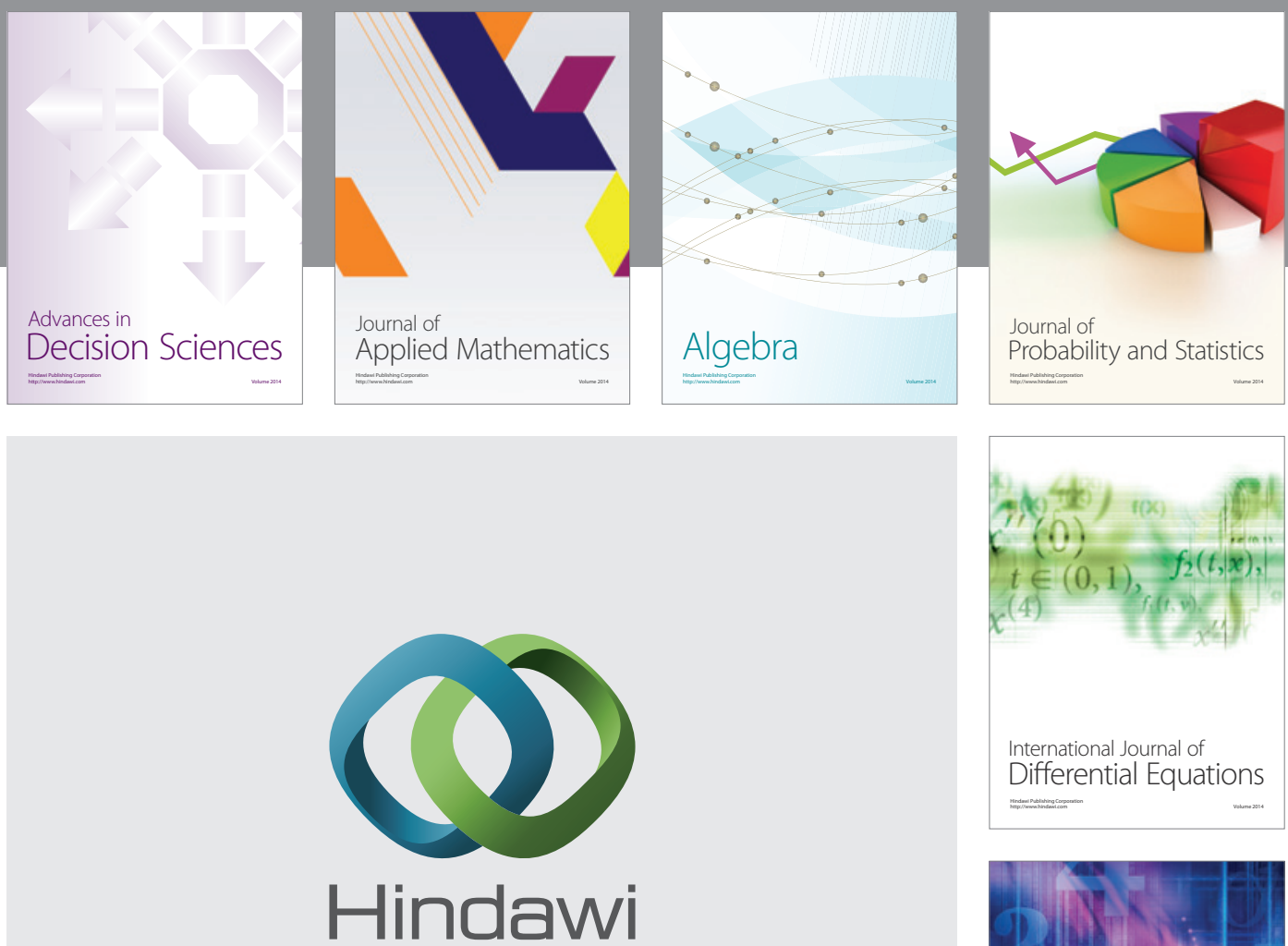

Submit your manuscripts at http://www.hindawi.com
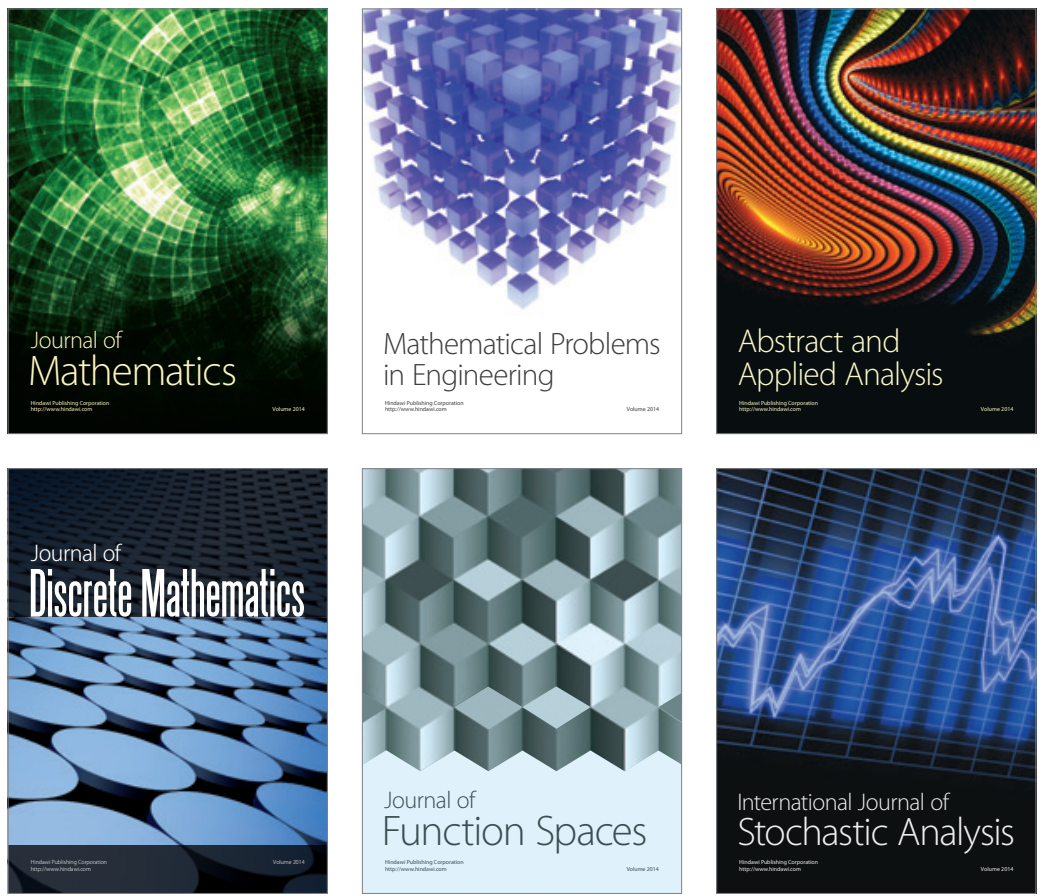

Journal of

Function Spaces

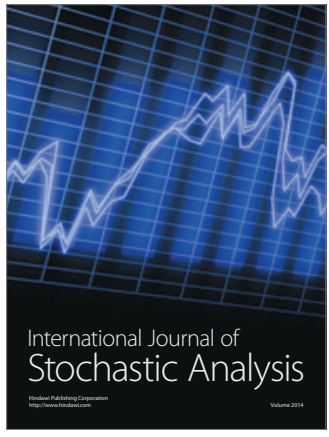

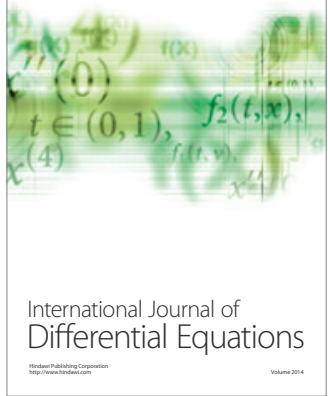
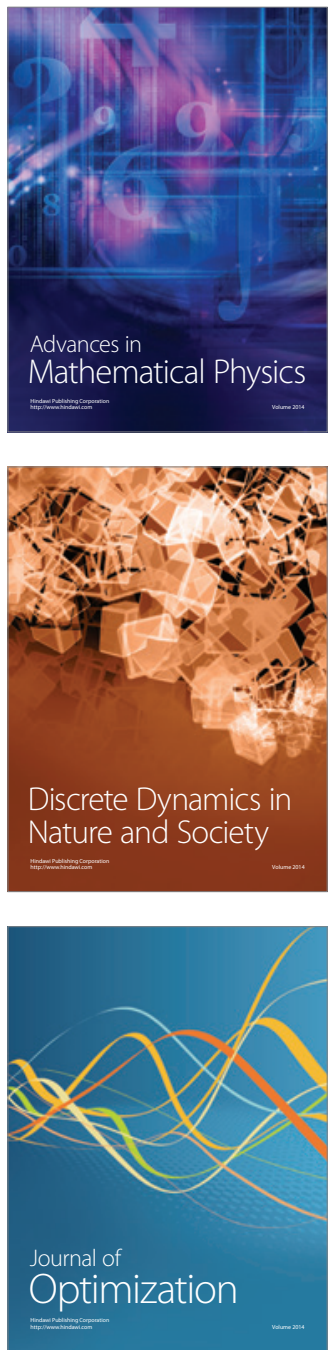